DoI: http://dx.doi.org/10.11157/sites-vol12issiid258

- ARTICLE -

\title{
ACADEMIC CRITIQUE OF NEOLIBERAL ACADEMIA
}

\author{
Andrew Whelan
}

\begin{abstract}
Academic critiques of neoliberalism do work: positioning their authors and their readers as subjects invested in the moral logic the critique establishes, and thereby moralising the collaborative accomplishment of the reader-writer relation. This relation and its constitution is a feature of contemporary leftist academic culture, and of the mechanics of critique as a social or 'solidarising' form of writing/reading. The academic critique of neoliberal academia warrants scrutiny particularly, given the casualisation of academic work and the emergence of a majority precarious academic labour force. Attending closely to it highlights some vulnerabilities of the academic critique of neoliberal forms, and illuminates the extent to which it constitutes its object in problematic ways: in terms of the political consequences or otherwise of critique as intellectual practice, of the model of subjectivity posited by the critique, and of the historical relations between academic practices and neoliberalism itself.
\end{abstract}

Keywords: Neoliberalism, critique, precariat, para-academics, academic culture

\section{INTRODUCTION}

...the university remains the most anomalous institution. Neither can capital eat it up, nor can it vomit it away.

(Edu-factory Collective 2010, 7)

If academic labour is going to be conceptualised, conducted, and described as a kind of critical struggle against the logics of 'neoliberalism' (or at least, as a presumably meaningful and consequential element to such struggle), there are a variety of specifics which need to be very clearly delineated, lest the endeavour remain at a somewhat general and unfocussed level. The costs of remaining at this level are high, intellectually and politically, and I aim to show how these costs are borne by some confusion as to the political and affective implications 
of academic work and academic writing and reading as social practices, and, when it comes to the critique of neoliberalism inside the university, a muddled and inconsistent account of academic subjectivity.

Better delineating these specifics would also go some way to clarifying the issue as to whether this is what academic labour-as-critique is, does, or should be - that is, as to what it would mean to say that academic work can be described as a critical struggle against the logics of neoliberalism. By extension, this involves calling for greater reflection on the contemporary politics of intellectual work in the institution that is the university, an institution not separate from, but thoroughly and intimately bound up in fantastic variants of the processes marshalled under the sign of neoliberal optimisation.

The site of the critique, the institution variously colonised by and to be defended from neoliberalism, has been 'ruined' for some time now (Readings 1996). The challenges are complex: diminishing budgets, multiplying audit mechanisms ensuring 'accountability', technological developments that appear to throw traditional teaching practices into question, closed publishing models, spiralling student-staff ratios, student loan debt crises, increasingly rigid and competitive research funding mechanisms, and perceived threats to academic freedom and independence. There is, consequently, a burgeoning literature in 'critical university studies' (zombieacademy 2010).

For the purposes of this article, the most salient issue in this context is the sustainability of the academic profession: the casualisation of academic work and the emergence of a majority academic 'precariat'. It is not easy to come by robust quantitative measures of the scale of this issue, but in Australia, for example, over half of all university teaching is provided by casual staff (Rea 2012). By head count, over sixty per cent of academic staff are casual (Hil 2013). There are an estimated 67,000 casuals employed in the sector in Australia; the majority of these are women (May 2011, 6). Almost half of all university staff are employed on fixed term contracts, and on average seven out of any ten new roles are casual positions (Lane and Hare 2014). Effectively, "the full-time, permanent, centrally-located teaching/research academic" is no longer the norm around which policy and practice can be formed' (Percy et al. 2008, 7).

Casual or sessional academic staff - 'para-academics' - are normally paid on an hourly rate under fixed term contracts, commonly of a semester's duration, though they are commonly re-hired every semester, often for a number of years (these are 'YIYOs' - 'year in, year outs'). They work with limited resources and no access to professional development, no job security, no entitlements to 
leave or sick pay, and no say in decision-making regarding how their work is structured, conducted, or assessed. Their pay ceases when the semester comes to an end. The summer recess in Australia is ordinarily of four months duration. It is common for sessional teaching staff to work at more than one university in order to make up sufficient income to survive, as there are limits to how many hours can be offered at an institution before the employer is obliged to provide benefits. Working hours routinely balloon beyond the nominal rate, particularly where there is an impression that student surveys and a good reputation with continuing staff impact on hiring decisions in the following semester. A significant component of core university work is thus conducted unpaid, on 'volunteer' labour. This presumably has some bearing on teaching 'quality' and 'standards', although this is not something senior university representatives are often noted drawing attention to. One interesting implication of this situation is how it articulates into the standardisation of assessment tasks, which now often requires setting particular word counts. The word count is a proxy for the piece rates the sessional staff receive to mark the student work. The tail of a 'flexible' workforce, a consequence of quite rapacious costefficiency logic, thus wags the pedagogical dog.

What follows is broken up into four sections. An account of academic culture as a culture of practice, which valorises intellectualism of specific kinds and in specific forms, is followed by a summary of the common themes and approaches in the academic critique of neoliberalism. The third section synthesises these accounts by way of a discussion of how academic critiques of neoliberalism in the university express the relationship between the reader and the writer, and thereby, how an under-articulated and contradictory model of subjectivity can be shown at the textual level in these critiques. The final section describes and problematises the neoliberal subject posited by the critique, before suggesting some alternative strategies to think through and with.

\section{ACADEMIC CULTURE AS CULTURE OF PRACTICE}

I start, then, with a descriptive commentary drawing on a kind of naïve cultural anthropology of academic life and work in the humanities and social sciences (what I am referring to here as 'academic culture'). The rationale for furnishing this description as a backdrop for the kind of analysis I will conduct in the following pages follows a particular socio-logic. It is worth labouring the point somewhat here, to better bring into focus the things which 'everyone knows' and which are 'obvious' about this context, and about the role played in it by the critique of neoliberalism (taken particularly as an exemplar of a broader tradition of critique). 
The professional academic lifeworld of the humanities and social sciences is permeated in many of the routine social rituals which mark it (conferences, seminars, $\mathrm{PhD}$ supervision meetings, undergraduate lectures and tutorials, abstracts, peer reviews and other 'backstage' academic documents and correspondence, informal conversations and so on), by arguments of a particular 'intellectual' hue. Especially favoured in this context are critical lines that purport to describe and declaim the world 'as it really is' - often through engaging with established critical positions. These intellectual or academic arguments are a currency; they are intellectual capital, and they are a real, poignant and human medium of social exchange. People care about these arguments. They are that which is honoured as special, meaningful, worthwhile, distinct from the sometimes tedious tasks that otherwise make up the course of the work. Where manually entering grades into an online database or rewording a subject outline to incorporate new learning outcomes is profane, these arguments are sacred.

It is good in this culture to make a good (strong, persuasive, compelling) argument well (graciously, wittily, stylishly, with subtle erudition). It is good to generate insight or - much the same thing - the sensation of it among witnesses, students and interlocutors. It is better still to make a good argument, of a moral cast: an argument which makes tangible some moral sense, some perception as to a perhaps previously overlooked or obscured moral issue in the taken-for-granted of the world. The contemporary critique of neoliberalism is an argument of this kind par excellence. Features of the world initially introduced (in the structure of the argument) as mundane or banal (reality TV, for example, or tertiary education policy), are suddenly discovered to reveal truths of the structure of global neoliberal capitalism (and in an interesting way, are thereby redeemed), truths that show the callousness, venality, and moral bankruptcy of the dominant order.

These sorts of argument can be productively contrasted with what Dorothy Smith calls 't-discourses' or text-mediated discourses: understandings of the world reproduced in textual form in such a way as to become normalised and reified in the course of their social/textual reproduction $(1999,158)$. The persistence of their textual form is such as to make the world in their own image, to invite and persuade people to act as though the world had the attributes the textual form maps on to it.

The idealised and most valued form these arguments can take is a textual one. The printed word is the most ontologically present one to navigate by. Texts and their producers are invoked in conversation as arbiters and evidence of 
expertise and experience. If you had read $x$, you would sagely nod your head in approval at this point. These texts are 'branded' in a number of ways: publishing venues matter, for instance - very much so in relation to texts produced locally. Some venues are more desirable, exclusive, and prestigious than others, often directly commensurate to their relative inaccessibility (to writers, and to readers, especially those readers who do not have access to a subscribing university library). This is not a trifling matter: it is the fabric out of which career success and failure is made.

Canonical texts are hallowed: invoking the names of the authors of these texts often literally authorises assertions as to the validity or otherwise of arguments - their 'truthiness'. Interestingly, some of the most vociferously hallowed canons are marked by absent, disfigured, or otherwise elliptical texts (as with Gramsci, or Lacan, or the missing texts of Bakhtin and Benjamin). These serve as idols or mascots of sorts, and subcultures can be made out in terms of the strictness of their adherence to the perspectives of particular figures (as with Gilles Deleuze, or Harvey Sacks). There are thus particularly textual means of advancing and legitimating the sorts of arguments we are considering here, to social ends - the social and the textual are, as it were, coterminous and simultaneous in their advancement of each other. In the domain of the critique of neoliberalism, caps are often doffed particularly (but not exclusively) in the directions of Wendy Brown, Michel Foucault, Michael Hardt and Antonio Negri, David Harvey, Thomas Lemke, and Nikolas Rose.

As well as forming the basis of much 'official' intellectual and social and pedagogical work in talk-in-interaction, these textualised arguments are similarly consecrated in further texts (like this one); such secondary texts consolidate the social and intellectual space as such. Why anyone bothers to write things down (aside from the competitive institutional injunction to do so - because it is what academics are required to do to get work, keep it, and move 'up' in it), why it is writing rather than something else (cycling, say, or singing, or growing vegetables), what the technology and materiality of writing does to thought, people, or anything else, or who the imagined audience is, are all seldom-addressed features of the culture. In a kind of bibliographic fetishism, these practices are taken self-evidently to be productive, and politically and socially valuable.

A careful and deep distinction is drawn and elided, therefore, between the work of writing (how that writing points constitutively at iterations of the world), and the work of work (how the labour of the institution and its reproduction are managed). This distinction is, in some fundamental sense, an 'imaginary' 
or an 'ideological' one. Writing, and its close relation, reading (for the writing is embedded in the culture of scholarly citation, and projects itself temporally forward in and through that culture), are simply and straightforwardly assumed to be the best ways of working through the argument, the best technologies of thought and of representation.

In this environment, these arguments contra neoliberalism are the 'bread and butter' of professional intellectual life for a significant number of social sciences and humanities academics. Not only do people care about them in and of themselves; they serve also as the terrain for professional and interpersonal status competitions and displays. These latter can be successful in professional terms to the extent that they align correctly with institutional and career imperatives (the article is well placed, the conference paper leads to collaboration on a grant application).

Yet in a number of senses they are actually much more important than mere 'bread and butter.' They actually claim to accurately describe the real world; which is to say, they claim to be truths. They claim, as corollary, an absolute and correct moral status. To disregard the argument (given its moral cast) is therefore to exhibit moral dereliction: you are told (the truth behind) something of what is wrong with the world, and you are unmoved; what kind of person does that make you? These are means of constituting a political reality of a sort, which invites certain rationally and affectively ideal orientations, and is disinclined toward others. Particular conceptions of the good society, and the good state, for example, are indexed by the critique.

Such arguments constitute the basis of intellectual community insofar as they successfully intertwine the cognitive, the rhetorical, the affective, and the moral for the community of practice that is this academic community. This intertwining, done well, is considered a desirable form of politically committed scholarship. Such arguments are not only one of the principal means by which academics in the humanities and social sciences come to know each other as allies and (perhaps it is utopian) to overcome the differences of their hierarchical existence - more precisely, to perform this overcoming. They are, more fundamentally, often the means by which younger academics and prospective academics are brought into these fields, insofar as they can be sustained in them. That is to say, such arguments function as a central means of social reproduction in the university. The critique of neoliberalism is in this sense a commodity, sustaining precarious life; a commodity which, like others, asserts: 'Buy this to escape consumerism' (Pillsbury 2006, 146). The institutional culture of the university, as a component of a broader order, entails the capacity 
for the system of intellectual production to successfully absorb, incorporate, and benefit from critique.

In terms of how the critique of neoliberalism can mobilise young people into study, we can begin to see the relations between neoliberal culture and the 'old' academic culture in that, perversely, considerations of the cost of engaging further, and of the career options or dearth thereof that might follow from doing so, would be precisely the sorts of gauche considerations which demonstrate the poverty of the neoliberal worldview. The 'monastic' element to academic culture thus subtends the economic and affective exploitation routine to the contemporary university.

The position being developed here is not simply a variant of the dismissive attitude encapsulated by the phrase 'tenured radicals'. Academic precarity, like leftist hyperprofessional academic ambition, is real, and is really deleterious. One of the consequences of the instrumentalisation of academic practice has been the endorsement of a very narrow model of academic professionalism as a positive value, with an extremely specific delineation of what this entails (minimally: this many publications, this many grant applications, this range in Likert scale student evaluations, this form and extent of 'community engagement' and so on). Discussions of power, politics, social justice, or what have you, are embraced as something that might be gestured toward in a predictably bracketed way for students, but this is not ordinarily expected to be followed through and brought to bear within the institution itself. This implies a vertiginous disjuncture across the conjunction of quietism and spirited careerism; insofar as concerns are raised, they are usually limited to anxieties about and efforts to protect 'the discipline', conceived of in an atomized and largely selfinterested fashion.

Longstanding and entrenched aspects of academic culture thus intersect all too neatly with the emergent marketised and instrumentalised university, in ways that tend not so much to stifle dissent as to render it an elaborate gesture, to redirect political capacity into particular, self-limiting circuits, rendering critical thought not just a 'theoretical' dissent, but an assimilable and 'manageable' one.

ACADEMIC CRITIQUE OF NEOLIBERALISM

As a concept, Clarke tells us, neoliberalism is 'omnipresent, omnipotent, and promiscuous' $(2008,135)$. Insofar as it is identifiable as a 'thing' in the world, neoliberalism is not a unitary thing; it is a lumpy, rather ad hoc descriptor 
produced by aggregating inconsistently collected components. Your list of neoliberal processes and mine are not the same, and the emphases in each list also differ. Things that appear 'neoliberal' in some contexts appear benign in others. Within ostensibly neoliberalised social spaces, oddly 'abandoned' or 'free' processes and dynamics can be discerned. To treat this contingent and opportunistic list of 'things we don't like' as a consistent, stable entity is a category error, a reification of dynamic, processual realities and negotiations. Neoliberalisation is not a coherent and tangible force in the world; it is a label ascribed to an unpredictable array of such forces in unpredictable motion, usually in dialogue with other, often contradictory forces.

On the political right, the term is simply dismissed outright as a leftist shibboleth:

Using 'neoliberal' is code for 'I am a left-winger who does not like markets. It is a leftist version of the secret handshake; a signal that the reader is with fellow travellers. It is especially useful for academics seeking overseas recognition and the globalised anti-globalisation movement (Norton 2001, 65).

The use of the term 'neoliberal' has the apparent benefit, as I aim to describe, not simply of bringing together fellow travellers, but of constituting imaginary collectives of likeminded critics, albeit in a fractured and impoverished imaginary. This is also at the risk of the term itself becoming an empty place-marker for that-which-must-be-critiqued. Boas and Gans-Morse go so far as to assert that neoliberalism is a 'conceptual trash heap capable of accommodating multiple distasteful phenomena without much argument as to whether one or the other component really belongs' $(2009,156)$.

This seems particularly evident in recent work, where neoliberalism is taken simultaneously to apply to at least three distinct forms or levels of social reality, in such a way as to highlight how these forms are inter-articulated in a totalising and monolithic system. The systematicity of the model, the 'transmission' of neoliberal processes across these levels, and the ontology underpinning this transmission, generally go unexplained.

Among these forms or levels, one is a whole raft of economic policies at national and international levels, and the institutional structures for the enactment and enforcement of such policies. It is in this domain of political economy that the term neoliberal is usually applied. The 'reforms' ascribed the label neoliberal are those which financialise or marketise existing social systems, in- 
troducing competitive market mechanisms into novel environments (particularly those previously administered by the state, such as the penal system, or education) and consolidating already existing mechanisms of this sort. This is 'economic rationalism', or less generously, 'market fundamentalism. The welfare state is eroded or withdrawn (the state instead 'cares' for corporate interests, as when banks are deemed 'too big to fail' and bailed out with public monies), and public wealth and resources are transferred into private hands - presently, under the guise of 'austerity'.

The term neoliberalism also applies to the political rationality, or ethico-political worldviews that function not just as justifications for these economic policies, but also as moral imperatives or injunctions for the remaking of the social world in the image of a market, narrowly construed. Here one encounters the perspectives justifying the reconstitution of public goods as private ones, framing this as a morally appropriate course of action, and normalising this reconstitution. This is sometimes described with reference to the Thatcherite assertion of 'the TINA doctrine': that 'there is no alternative', and elaborated also by reference to Thatcher's assertion that 'there is no such thing as society'. According to this line, neoliberalism is a hegemonic discourse wherein individuals and families are moral agents responsible for their own wellbeing and success, such that state mechanisms designed to salve the structural consequences of speculative capitalist markets (such as homelessness following mortgage foreclosure) are deemed both inefficient (markets could do this work better) and morally problematic (facilitating a 'culture of poverty' and so on).

This political rationality is paradoxical in its effects in the public sector, in that increasing bureaucratisation occurs in the service of marketisation (supposed to 'roll back' the state), where this marketisation was originally proposed as a means of generating cost-saving efficiencies. In OECD countries, these efficiencies have not appeared: the proportion of GDP accounted for by government spending shows instead a modest increase in the period of time since 1980 (Flew 2014, 55). The state does not step away from the social; rather, state interventions are moralised in innovative ways (as when welfare reform becomes a means of implementing 'family values'). The moral aspect to this political rationality and its effects is also gendered, in that 'feminised' welfare state resources (for example, remittances to single parents) are not simply cut; the state is 'masculinised', with funding reallocated to 'law and order' and military agendas.

Public sector work in the context of these developments (which are also referred to as 'new public management') is 'flexibilised' in rather particular direc- 
tions: decision-making power is often consolidated in the hands of expanding numbers of managerial and administrative staff. The growth in the numbers of such staff employed in Australian universities since 1989, for example, far outweighs the growth in the numbers of teaching staff, despite a doubling of student numbers in that time period (Dobson 2010,32).

In this sense, the practice and the ideology of neoliberalism are described as being at odds with one another, which is to say, as an ideological agenda, neoliberalism serves the interests of powerful groups. This really only appears inconsistent if we imagine the neoliberal agenda 'means what it says'. In fact, this agenda appears to be applied selectively in the pursuit of transferring economic and political benefits to elites. The overall implications of these trends are described as involving a steady erosion of civil liberties and the rule of law, the decline of democratic institutions and democratic participation, the consolidation of wealth, and a concurrent rise in social inequality.

Perhaps most notably for present purposes, neoliberalism is also described as a governmentality à la Foucault, a process of subjectification, which constitutes neoliberal subjectivities. To put this more simply, neoliberalism 'makes people': subjects invoked by and appropriate to the managerial techniques and market logics by which they are governed. It saturates the grounds by which people come to understand themselves as subjects, and come to understand their rights and responsibilities as regards each other and the broader social forces they encounter.

Citizenship is redefined as consumer sovereignty, with acquisition and consumption the only meaningful incentives to action. The dominant model of the individual becomes a rational-choice style utility-maximising 'produser' (Bruns 2008), who understands her own responsibility to render herself as a commodity, as an entrepreneurial self keen to avail of the opportunities for self-actualisation and 'personal growth' the market brings. Success or failure in this market is conceptualised as a moral effect, the consequence of personal choice rather than a structural outcome. History and community are evacuated, and the individualised self is envisioned instead in terms of her 'innate' attributes and capacities. This self or 'subject-effect' is made in the image of the discourse of neoliberalism and populates its institutions. This spectre of the entrepreneurialised self haunts the academic critique of neoliberalism.

The institutions she populates include the university itself, the principal site from which this perspective is disseminated. For example, Commisso describes neoliberal governmentality as something 'which infiltrates all aspects 
of university life, orientating the ethical and subjective dispositions of academic workers and molding their identities' $(2013,157)$. In a similar vein, Gill describes how critical scholarship about neoliberalism directs our attention to new and emerging forms of discipline, which operate as technologies of selfhood that bring into being the endlessly self-monitoring, planning, prioritising 'responsibilised' subject required by the contemporary University. She requires little management, but can be accorded the 'autonomy' to manage herself, in a manner that is a far more effective exercise of power than any imposed from above by employers $(2009,231)$.

Neoliberalism can thus be said to have economic, political, social, institutional, subjective, affective and material properties. In terms of the critique, it is in some sense not 'correct' to isolate out these customary designations; doing so weakens the critique by falsely segmenting a system which is a complex totality - a 'social factory'. This system is described as being in the service of, and more or less explicitly devised and implemented by, a resurgent capitalist class. It is worth noting that however one feels about this account, there is no doubt that wealth and power have in fact been concentrated in recent years to an extent unprecedented since the Great Depression. This makes a good analytical grasp of contemporary academic critique and its social functions - the social morality and value of critique - all the more imperative.

In the terms customarily given by this kind of account then, neoliberalism, like a spiritual energy, suffuses everything. It is imagined as a kind of shape-shifting force, which moves across fields customarily taken to be discrete, reconstituting these fields as it goes. For example, as Shore puts it in a description of audit as a feature of neoliberal culture in its managerial guise:

audit has a life of its own - a runaway character - that cannot be controlled. Once introduced into a new setting or context, it actively constructs (or colonizes) that environment in order to render it auditable. The effects are irreversible $(2008,292)$.

One such effect is the production of those neoliberal subjects described by Gill. Here, neoliberalism jumps, or perhaps creeps, from a bureaucratic management technique, into those so managed. Without a more explicit account of how this 'transmission' works or should be understood to work, neoliberalism appears as something of a miasma, and seems therefore also to invite this kind of super-soaker response, which does not involve differentiating or specifying levels or locations of analysis, or investigating and describing precisely the particulars and mechanics of transmission in everyday administrative practice. 
In a discussion of what it is that makes resistance difficult in the neoliberal university, Petersen fleshes out this 'installation' of neoliberalism in the individual, its transmission, in terms of 'enrolment'. She describes the various 'hooks' or enticements by which academics are rendered compliant and appropriately responsive neoliberal subjects:

For academics who have become passionately attached to constructs of themselves as 'good colleagues', as good co-operators, this may therefore be the hook that finally ensures enrolment, as refusing to 'help out', to turn down a distressed colleague, is unpalatable, unthinkable. The ultimate problem becomes that it is nice people who enforce monstrous policies $(2009,419)$.

Parasitically, neoliberalism hijacks the moral goodness of good academics, their collegiality, in order to get them to do what they know to be wrong. This produces a horrible inversion, where 'nice people' enact the monstrosity of neoliberalism, and those who refuse or resist thereby become 'not nice'.

Enrolment into complicity and compliance, by Petersen's account, preys on the 'niceness' of academic subjectivities: this is how academics become neoliberal subjects, how neoliberalism is transmitted into them. Why academics are supposed to, or want to, think of themselves as 'good' remains an open question. Peterson opens the space also for those academics who have not become passionately attached to constructs of themselves as 'good colleagues'. And we could just as easily have this the other way around, in that 'nice' or 'good' people, people invested in teaching, for example, do not generally go well rewarded in the contemporary university, earnestly comply though they might. The institutional reward system favours rather a kind of organisational sociopathy, as we have been hearing, a highly self-interested and 'not nice' subject, who abandons all forms of collegial practice (for example, peer review) that cannot be rendered part of the personal brand for the purposes of career advancement:

All intellectual engagements that are not directly output-oriented become increasingly phased out because they become practically disadvantageous. In summary, the audits entice academics to become entrepreneurs, thereby framing education and knowledge in terms of investment and profit and subsuming them under the excessive logic of capital. The fruitful relationship between teachers and students consequently degenerates into a service provider-client contract that forecloses alternative kinds of pedagogy as the 'enterprise self' becomes the dominant subject at university (Illner 2011, 79). 
We can go further here, by reflecting again on how the ground for the 'not nice' neoliberal subject is established by the nature of pre-existing academic culture. The latter is careless, in that the privileging of rationalism, logic, and objectivity, and the artificial distinction between these and emotion and affect, functions in conjunction with neoliberal 'reform' to hierarchise academic work along gendered lines: research is 'male' and individuated and intellectual, teaching is 'female' and relational and affective (Lynch 2010). In this context, thinking of, and attempting to conduct, university work as collaborative and relational literally does not pay.

However this 'transmission' of neoliberalism is imagined then, it implies a model of subjectivity, or more specifically, a model of the relation between self and collective. The tendency with this model is to so thoroughly 'sociologise' power that individual agency tends to disappear. This follows reasonably enough from the 'post-realist' imagining of the social as a kind of assemblage of assemblages, where the discreteness of forms, institutions, technologies, subjects and so on is treated as an analytical artefact of fuddy-duddy, anallyretentive empiricists. The neoliberalisation of the subject, in terms of the 'transmissions' described above, implies what one could call a 'weak' model of subjectivity. Either individual, isolated academics somehow succumb to neoliberal enticements, one by one, or they are 'guilt-tripped in' out of misguided loyalty to their students, their peers, and their ethos of collegiality. In either case, the culture of the university itself facilitates the transmission, and the academic subjectivity is described as easily co-optable. Neoliberalism is irresistible.

WRITING THE CRITIQUE OF NEOLIBERALISM AS SOLIDARISING SOCIAL PRACTICE

The critique of neoliberalism as an intellectual practice of writing, conducted as a collaborative but dispersed venture by professional academics in the humanities and social sciences, produces a morally problematised 'outside': the neoliberal order. The course of this production entails, implicitly or explicitly, an 'inside' also; an apparently unproblematic or at any rate less problematic space, where the writer and the reader can pause and come to know each other, come to know that others like them are also engaged in the struggle, and come to know and reaffirm what is right and what is wrong through the conduct of the critique.

The critique of neoliberalism thereby constitutes an imaginary grounding for a 'solidarising we' or 'us', who have come to grips with what makes for good moral and ethical standing, or who come to enact and embody such standing 
through their reading/writing. These attributes could be gestured to across a range of texts, but in the interests of space, I will limit myself here to a few specific examples.

Consider as an instance of the kind of textual sociability I am interested in, some remarks in the introduction to Patricia Ventura's Neoliberal Culture (2012). On the first page of this book:

while neoliberalism is thought of around the world as an Americanled form of capitalist imperialism, in the US, neoliberalism is rarely part of the popular discourse outside of academic and progressive circles $(2012,1)$.

Or:

I use the term [structure of feeling] here because it continues to have resonance in the US context since this structure rests largely below the consciousness of most non-academics and non-progressive activists $(2012,3)$.

And again:

we are left with the strange situation in which much of the world actually sees the US as a neoliberal imperial power, while many Americans operating outside academic and progressive circles remain unaware of what neoliberalism even is $(2012,7)$.

I am not citing this text with the intention of casting it as poor scholarship. Nor do I claim that it stands as a general example of what 'critique of neoliberalism' looks like - just as neoliberalism is heterogeneous, so also is its critique richly variegated. But these three quotations serve well as a way in because of the work they do so early in the text, and because of the presumed alliances and 'like-mindednesses' they postulate. Considering this reverberation across the opening of the book highlights that imagined 'solidarising we', and, not incidentally, some limits to this solidarity.

According to Ventura's wording, there are academic and progressive circles, invoked in that order, in the United States, where knowledge of what neoliberalism is circulates. That is to say, there are people in the United States outside of these circles who do not even know what neoliberalism is. They are a presumably large cohort, negatively defined as 'non-academics and non-progressive 
activists. Ventura does not by the latter, one assumes, mean reactionary activists - the Tea Party perhaps - unless as a subset of all those who are simply not activists of the progressive sort (whatever 'progressive' is taken to mean in this context).

Ventura also refers to these people as 'Americans', although those peoples presumably span the two continents of the Americas outside the borders of the US, and indeed live further afield also. These are straightforward observations that derive from the surface of the text, they pertain to how the text flows as a moral process that in-scripts and ex-scripts, in some ways casually and unwittingly, and in others systematically and explicitly. Are these features of neoliberalism as a colonising discourse, shaping subjectivity? Or something else?

Neoliberalism is 'below consciousness' for these people, it is their structure of feeling, it shapes them as subjects (they are in Ventura's language 'governed through freedom'), but they (unlike us) cannot see or grasp that. Moreover, it matters especially that this is the case in the United States (as opposed to anywhere or everywhere else). It matters that this is the case in the United States, firstly, because people outside of that country evidently see it as somehow 'leading' neoliberalism. This implies that United States residents outside of academic and progressive circles should probably be embarrassed (and possibly admonished) about their parochialism, provincialism, and inability to grasp what the rest of the world thinks of them, their government, and their active involvement in the global regime. It implies also that in 'much of the world', or 'around the world' (that is, presumably, all or many places which are not the US), there is agreement that the US leads the neoliberal charge. That is, paradoxically, that in a way those ignorant US residents are validated in their complacency; they are after all at the centre of the empire and thereby the centre of the world anyway.

Meanwhile, in these other parts of the world, many sensible and right-feeling people (not just academics and progressives, as surely in these other places not all people are in those camps) rightly sit in judgement on the US and its residents. This is a rather poor assumption, because ideas about what neoliberalism is, ideas about what the US is, ideas about what the US is doing (locally or further afield), and ideas about how what the US is doing is neoliberal all vary to astonishing degrees. It is also a rather poor assumption given that many people quite likely do not particularly think about the US at all, as the sources of many of their troubles, sadly, are a good deal more uncomfortably immediate. 
It matters that this is the case in the United States, secondly, because the academic and the progressive are conjoined in their conceptual literacy and their political consciousness by this phrasing. The progressive is justified by its academic support (academics being presumably knowledgeable and therefore 'right' people); and the academic is legitimated by its progressive alliances, which is to say, its political purchase and consequence outside of the academy. Both are then tacitly linked with those many people 'outside' the US who also know these truths. Thus regular US citizens (who are also, presumably, in neoliberal discourse, 'taxpayers', and 'consumers of educational products' or similar) are again othered in and excluded by the logic, all the better to position us as readers in the same circles, with the academics and progressives. As Barnett puts it:

For all its apparent critical force, the vocabulary of 'neoliberalism' and 'neoliberalization' in fact provides a double consolation for leftist academics: it supplies us with plentiful opportunities for unveiling the real workings of hegemonic ideologies in a characteristic gesture of revelation; and in so doing, it invites us to align our own professional roles with the activities of various actors 'out there', who are always framed as engaging in resistance or contestation (2005, 9-10).

This positioning can also be conducted more explicitly and poetically. Both zeroing in on and demonstrating the issue I am trying to get at, Moten and Harney describe the academic precariat as follows:

Maroon communities of composition teachers, mentorless graduate students, adjunct Marxist historians, out or queer management professors, state college ethnic studies departments, closed-down film programs, visa-expired Yemeni student newspaper editors, historically black college sociologists, and feminist engineers. And what will the university say of them? It will say they are unprofessional (2004, 104).

They contrast this group with (tenured) 'critical academics':

does the critical academic not teach how to deny precisely what one produces with others, and is this not the lesson the professions return to the university to learn again and again? Is the critical academic then not dedicated to ... the impoverishment, the immiseration, of society's cooperative prospects? This is the professional course of action. This enlightenment-type charade is utterly neg- 
ligent in its critique, a negligence that disavows the possibility of a thought of outside, a nonplace called the Undercommons - the nonplace that must be thought outside to be sensed inside, from whom the enlightenment-type charade has stolen everything for its game $(2004,112)$.

Here, critique as professional academic practice is complicity, to the extent that it is predicated on the labour of the 'Undercommons', the para-academics who populate and fuel the institution. The academic subject is thus divided; lines are drawn, following well-established boundaries. When the barricade goes up, which side will 'we' be on?

It is possible, then, to attend to how the critique of neoliberalism expresses the reader-writer relation, explicitly and implicitly: who is 'us' here, and who is 'not us'? Derrida has a memorable opening to a paper:

If we could say we (but have I not already said it), we might perhaps ask ourselves: where are we? And who are we in the university where apparently we are? What do we represent? Whom do we represent? Are we responsible? For what and to whom? $(1992,3)$.

These are engaging questions, questions worth pursuing; perhaps another such question would invite reflection on the extent to which we might be able to write our way out of or through these kinds of questions, in and from the university.

The question I have been raising concerns the 'solidarising we' of the text in the critique of neoliberalism: how to think about how this relationship is written, and how the way it is written relates to the kind of subjectivity the critique itself imagines. That is to say, it seems to be worth reflecting on the 'weak' subjectivity that comes to be colonised by neoliberalism, according to the content of the critique-as-written, and the ('strong') resistant subjectivity of the reader-writer as they come to understand their commonality, in the form of the critique-as-written. The discrepancy between these two is indicative of a limit. It can be sensed, a shadow in the text, which is a shadow in the strategy of institutionalised intellectual labour as politics.

WHO CARES?

This limit can be traced with a bolder line. There is a doppelgänger in our midst who is not-us, and whose invocation serves to give us 'us'. The subject-effect 
who has appeared, like an ectoplasm, from the critical account of the neoliberalisation of the university, she has been sent by the critique to do a bad job, and she doesn't do it well.

She appears at first rather like Golyadkin Jr. in Dostoyevsky's The Double. Our superiors like her better than us in the office, and she will get a promotion before we do. She has published more articles than us, in journals we feel are beyond our reach. Her web profile specifies an alarming dollar value of grant funding brought in and apparently spent, although we privately believe this is not a marker of anything, other than perhaps a capacity to fill out application forms, or the unimaginative gullibility and narrow-mindedness of funding panels. She is better at her job than we are at ours, because she fits (she was in a sense engineered for) the template prescribed by the neoliberal reformation of the role and its requirements so well: a job we couldn't possibly do, either well or in good faith, because we are nice people. Our failure and alienation here is the sign of our authentic humanity, in the face of her machine-like, enterprise self, can-do neoliberal enthusiasm. She fits in seamlessly in our own world made alien to us, better than we do. We are thus thoroughly supplanted.

She is ultimately unconvincing in her role in this horror story, because as a character she is so incongruent with the 'we' intent on despatching her through the powers of critique. It is a story with some good frights, but by the end it gets a bit silly. This is so because the telling of the story is a bad job: ostensibly in defence of academic culture, and often in the name of the precarious multitude of the Undercommons, the telling of the story draws for its effect on what Nair calls 'class shock' (2014). The bitter tragedy of the casualisation of academic work is that the new majority of para-academic workers denied tenable roles at the institution feel, rightly so, that they were actually good at the meritocratic game and invested in the right way in themselves as human capital: they went to university and went as far in that engine of social mobility as they could. When they - like 'us' - did so, it was for the right, old-fashioned reasons - they weren't entrepreneurial subject-effects (Gerrard 2014). Yet now academic meritocracy is shown to be the fiction it has always been: the ceiling is a good deal lower than it had seemed and the ladders have all been pulled up already. The outrage mobilised and leveraged at this both inside the institution and in gestures toward it aimed at those outside is thus dismally bourgeois; the vision the middle class have of their own downward mobility, and the intimate relationship between this vision and the dreadfulness of not just permanent economic insecurity, but the permanently economically insecure - poor people. How awful, to end up (with people) like that! When we not only did everything we were supposed to do, but did it better than everyone else, and cleverly. 
The critique is therefore of interest precisely to the extent that its horizon of imagination shows us the limits of 'us' in the narrative. The scary story it tells is not anywhere near as frightening as it should be, because it leverages, rather than pursues, the privilege and exclusion on which the outrage is predicated. The argument, 'we shouldn't have to work and live like this', is not the most compelling argument. A more compelling argument might be, 'nobody should have to work and live like this'.

If this is so, it would presumably entail further reflection on the historical role of the university as a function and locus of changing patterns of class reproduction, including and especially prior to the ascendance of talk about neoliberalism. This role, needless to say, has not been universally and at all times in the service of human progress and emancipation. This in turn has some bearing, if the critique is supposed to inform or invite some kind of political action.

The academic critique of neoliberal academia, I have argued, is not necessarily as productive as it could be. This is perhaps related to its commitment to impoverished and underspecified models of power and of subject formation, derived from interpretations of Foucault. These models are themselves belied by the textual form of the critique itself. Perhaps this is also related to the curious academic preoccupation with critique itself as a kind of action. If critique is action, it is action of an indirect kind. Critique, Mansfield and Matthews argue, is of little value if it does not inform and translate into 'a positive engagement with institutional practices' $(2011,7)$.

This kind of engagement takes many forms (see, for example, Deslandes 2013, Mason and Purcell 2014). Further such forms can be developed, both overt and covert, given that the following is certainly the case; people continue to show up in universities. One important reason why they do so is because they care. Their being there is caring, it is caring as a doing. The workings of the university - the university as an everyday accomplishment - are brought into being through their ongoing taking care of things there. But what does this mean? What do they care about, and why?

For those who recognise in the academic critique of neoliberal academia the strange derangement and slow decay of their own lives, it can be helpful to reflect actively on what it is that is cared about and how that caring is done exactly. As Puig de la Bellacasa suggests, there is much to be said for 'curiosity about how other people keep care going in the dislocated world of contemporary academia and its corollary, the anxious delirium of permanent reorganization' (2012, 212). 
As a 'doing', that care and its manifestation likely involve some of the various practices and rituals described above; for instance, encounters with students, reading and writing, ideas expressed in particular forms. These practices and rituals often seem to involve the articulation and development of relational ways of knowing, and of experiencing things. Whatever the loci of care are, their particulars can be specified and enunciated. This is an important task, not least because the organisation of these various practices and rituals into 'university work' is partial, contingent, and the accidental consequence of complex historical dynamics. There is no requirement that they be sutured together eternally for any of them to be sustained. Moreover, it is possible to work out who cares in similar ways, perhaps (though not necessarily) for similar things, at other locations, to make this commonality known, and thereby, to make alliances with depth beyond class shock.

Conversely, it is possible to enumerate exactly what processes, practices, procedures and policies stymie or degrade that which is worth caring about. We can aggregate them as 'neoliberalism', but doing so seems an unproductive smudge. They have extremely specific manifestations and are in many cases explicit and accountable artefacts of modes of administration and governance. These require enumeration and the production of evidence as to their real effects. And these too should be enunciated, as a means also to refuse and reject them. This project also warrants its own, deep, care.

\section{ACKNOWLEDGEMENTS}

I am indebted to Catherine and Emil Rogers, Nicola Evans, Lisa Slater, Chris Prentice and Jenny Lawn, and the anonymous reviewers for their invaluable feedback and comments on earlier versions of this paper.

\section{REFERENCES}

Barnett, Clive. 2005. 'The consolations of "neoliberalism"' Geoforum 36 (1):7-12.

Boas, Taylor and Jordan Gans-Morse. 2009. 'Neo-liberalism: From new liberal philosophy to anti-liberal slogan.' Studies in Comparative International Development $44(1): 137-161$.

Bruns, Axel. 2008. Blogs, Wikipedia, Second Life and Beyond: From Production to Produsage. New York: Peter Lang Press.

Clarke, John. 2008. 'Living with/in and without neo-liberalism.' Focaal - European 
Journal of Anthropology 51:135-47.

Commisso, Giuliana. 2013. 'Governance and conflict in the university: the mobilisation of Italian researchers against neoliberal reform.' Journal of Education Policy 28 (2):157-177.

Deslandes, Ann. 2013. 'Zombie solidarity.' Ann Deslandes. Accessed January 26, 2015. https://xterrafirma.wordpress.com/2013/02/05/zombie-solidarity/.

Derrida, Jacques. 1992. 'Mochlos: or, the conflict of the faculties.' In Logomachia: The Conflict of the Faculties, edited by Richard Rand, 3-34. Lincoln: University of Nebraska Press.

Dobson, Ian. 2010. 'Uneven development: The disjointed growth of university staffing since Dawkins.' People and Place 18 (1):31-38.

Edu-factory Collective. 2010. 'The double crisis: living on the borders.' Edu-Factory Journal o:4-9. Accessed January 27, 2015. http://www.edu-factory.org/ edu15/webjournal/no/Edu-factory.pdf.

Flew, Terry. 2014. 'Six theories of neoliberalism.' Thesis Eleven 122 (1):49-71.

Gerrard, Jessica. 2014. 'All that is solid melts into work: self-work, the "learning ethic" and the work ethic.' The Sociological Review 62 (4):862-879.

Gill, Rosalind. 2009. 'Breaking the silence: the hidden injuries of neo-liberal academia.' In Secrecy and Silence in the Research Process: Feminist Reflections, edited by Roisin Ryan-Flood and Rosalind Gill, 228-244. London: Routledge.

Hil, Richard. 2013. 'Plenary Address.' Paper presented at Academic Work Cultures and Wellbeing: Strategies for Transformation, Macquarie University, Sydney, May 2.

Illner, Peer. 2011. 'Against audited education: the emergence of an activist pedagogy', Edu-Factory Journal 1: University Struggles and the System of Measure: 68-81. Accessed January 27, 2015. http://www.edu-factory.org/wp/wpcontent/uploads/2011/og/Illner.pdf.

Lane, Bernard and Julie Hare. 2014. 'Demand drives increase in casual staff at universities.' The Australian, February 5. Accessed January 25, 2015. http:// 
www.theaustralian.com.au/higher-education/demand-drives-increase-incasual-staff-at-universities/story-e6frgcjx-1226817950347? $\mathrm{nk}=37 \mathrm{c} 8937637 \mathrm{e}$ 587af405e2ce73f940c79.

Lynch, Kathleen. 2010. 'Carelessness: A hidden doxa of higher education.' Arts and Humanities in Higher Education 9 (1):54-67.

Mansfield, Nick, and Nicole Matthews. 2011. 'Disciplining Innovations.' Cultural Studies Review 17 (2): 4-10.

Mason, Kelvin, and Mark Purcell. 2014. 'Beyond the defence of the public university.' In The Para-Academic Handbook: A Toolkit for Making-Thinking-Creating-Acting, edited by Alex Wardrop and Deborah Withers, 87-106. Bristol: HammerOn Press. Accessed December 3, 2014. http://www.hammeronpress. net/PHA_PDF_sPREADS.pdf.

May, Robyn. 2011. 'Casualisation; here to stay? The modern university and its divided workforce.' Paper presented at the 25th Association of Industrial Relations Academics of Australia and New Zealand (AIRAAnZ) Conference. Accessed January 27, 2015. http://www.nteu.org.au/library/view/id/1321.

Moten, Fred, and Stefano Harney. 2004. 'The university and the undercommons: seven theses.' Social Text 79, 22 (2):101-115.

Nair, Yasmin. 2014. 'Class shock: affect, mobility, and the adjunct crisis.' Contrivers Review, October 13. Accessed January 15, 2015. http://www.contrivers.org/ articles/8/.

Norton, Andrew. 2001. 'Naming the Right: From the new right to economic rationalism to neoliberalism.' Quadrant 45 (12): 62-65.

Percy, Alisa, Michele Scoufis, Sharron Parry, Allan Goody, Margaret Hicks, Ian Macdonald, Kay Martinez, Nick Szorenyi-Reischl, Yoni Ryan, Sandra Wills, and Lynn Sheridan. 2008. The RED Report, Recognition - Enhancement - Development: The contribution of sessional teachers to higher education. Sydney: Australian Learning and Teaching Council.

Petersen, Eva. 2009. 'Resistance and enrolment in the enterprise university: an ethno-drama in three acts, with appended reading.' Journal of Education Policy 24 (4): 409-422. 
Pillsbury, Glenn. 2006. Damage Incorporated: Metallica and the Production of Musical Identity. New York: Routledge.

Puig de la Bellacasa, María. 2012. "Nothing comes without its world": thinking with care.' The Sociological Review 6o (2):197-216.

Rea, Jeannie. 2012. 'National Survey reveals a Casual Academic workforce struggling to make a living and do their job.' National Tertiary Education Union. Accessed January 15, 2015. http://www.nteu.org.au/article/National-Surveyreveals-a-Casual-Academic-workforce-struggling-to-make-a-living-anddo-their-job-12792.

Readings, Bill. 1996. The University in Ruins. Cambridge: Harvard University Press.

Shore, Cris. 2008. 'Audit culture and illiberal governance: universities and the politics of accountability.' Anthropological Theory 8 (3):278-299.

Smith, Dorothy. 1999. Writing the Social: Critique, Theory, and Investigations. London: University of Toronto Press.

Ventura, Patricia (2012). Neoliberal Culture: Living With American Neoliberalism. Burlington: Ashgate.

zombieacademy. 2010. 'Zombie Research.' Zombies in the Academy. Accessed January 27,2015 . https://zombieacademy.wordpress.com/zombie-research/. 
Article Whelan 
SITES: New Series · Vol 12 No 1 2015 